\title{
Exploring the Role of Gut Bacteria in Health and Disease in Preterm Neonates
}

\author{
Jimmy Kok-Foo Lee ${ }^{1,2}{ }^{\oplus}$, Loh Teng Hern Tan ${ }^{1}\left(\mathbb{D}\right.$, Amutha Ramadas $^{1}{ }^{\circledR}$, \\ Nurul-Syakima Ab Mutalib ${ }^{3, *(D)}$ and Learn-Han Lee ${ }^{1, *}$ (D) \\ 1 Novel Bacteria and Drug Discovery Research Group (NBDD), Microbiome and Bioresource Research \\ Strength (MBRS), Jeffrey Cheah School of Medicine and Health Sciences, Monash University Malaysia, \\ Bandar Sunway 47500, Selangor Darul Ehsan, Malaysia; jimmy.lee@monash.edu (J.K.-F.L.); \\ loh.teng.hern@monash.edu (L.T.H.T.); amutha.ramadas@monash.edu (A.R.) \\ 2 Clinical School Johor Bahru, Jeffrey Cheah School of Medicine and Health Sciences, Monash University \\ Malaysia, Johor Bahru 80100, Malaysia \\ 3 UKM Medical Molecular Biology Institute (UMBI), UKM Medical Centre, Universiti Kebangsaan Malaysia, \\ Kuala Lumpur 56000, Malaysia \\ * Correspondence: syakima@ppukm.ukm.edu.my (N.-S.A.M.); lee.learn.han@monash.edu (L.-H.L.)
}

Received: 28 July 2020; Accepted: 19 September 2020; Published: 23 September 2020

check for updates

\begin{abstract}
The mortality rate of very preterm infants with birth weight $<1500 \mathrm{~g}$ is as high as $15 \%$. The survivors till discharge have a high incidence of significant morbidity, which includes necrotising enterocolitis (NEC), early-onset neonatal sepsis (EONS) and late-onset neonatal sepsis (LONS). More than $25 \%$ of preterm births are associated with microbial invasion of amniotic cavity. The preterm gut microbiome subsequently undergoes an early disruption before achieving bacterial maturation. It is postulated that bacterial gut colonisation at birth and postnatal intestinal dysbacteriosis precede the development of NEC and LONS in very preterm infants. In fact, bacterial colonization patterns in preterm infants greatly differ from term infants due to maternal chorioamnionitis, gestational age, delivery method, feeding type, antibiotic exposure and the environment factor in neonatal intensive care unit (NICU). In this regard, this review provides an overview on the gut bacteria in preterm neonates' meconium and stool. More than $50 \%$ of preterm meconium contains bacteria and the proportion increases with lower gestational age. Researchers revealed that the gut bacterial diversity is reduced in preterm infants at risk for LONS and NEC. Nevertheless, the association between gut dysbacteriosis and NEC is inconclusive with regards to relative bacteria abundance and between-sample beta diversity indices. With most studies show a disruption of the Proteobacteria and Firmicutes preceding the NEC. Hence, this review sheds light on whether gut bacteria at birth either alone or in combination with postnatal gut dysbacteriosis are associated with mortality and the morbidity of LONS and NEC in very preterm infants.
\end{abstract}

Keywords: gut bacteria; gut microbiome; preterm neonates; mortality; dysbacteriosis

\section{Introduction}

Prematurity is the leading cause of global under-5 deaths from the year 2015 [1]. Preterm babies are born from 22 weeks to 36 weeks 6 days of gestational age. They account for $11.1 \%$ of 135 million live births in the world in 2010 [2]. The care of preterm infants is both labour intensive and consumes a major portion of neonatal intensive care unit (NICU) resources [3]. The very preterm infants born less than 32 weeks gestation comprises $15.6 \%$ of preterm births and have a high risk of mortality and morbidity [4]. It was reported that the survival till discharge of less than $80 \%$ for the very preterm infants and very low birth weight (VLBW) infants in Malaysia [5]. The survival of very preterm 
infants under the birth weight category of 500 to $<1000 \mathrm{~g}$ and 1000 to $<1500 \mathrm{~g}$ were $53.4 \%$ and $89.7 \%$, respectively. Meanwhile, the VLBW infants in Canada achieve survival rates of $85.5 \%$ and $97.5 \%$ for the two birth weight categories [6].

The survivors of infants born VLBW $(<1500 \mathrm{~g})$ and especially the extremely low birth weight $($ ELBW $)(<1000 \mathrm{~g})$ are at a high risk of serious pre-discharge morbidities. These morbidities include early and late-onset neonatal sepsis (LONS), necrotising enterocolitis (NEC), poor somatic growth besides intraventricular haemorrhage, periventricular leukomalacia, retinopathy of prematurity, patent ductus arteriosus and chronic lung disease. The Canadian Neonatal Network [6] reported 67\% survivors without any of the 6 morbidities of severe neurological injury [(Intraventricular haemorrhage (IVH) III \& IV, periventricular leukomalacia (PVL)], retinopathy of prematurity (ROP) $3 \& 4$, oxygen use at 36 weeks or discharge, patent ductus arteriosus (PDA) requiring surgical ligation, NEC stage 2 or 3 and culture proven early-onset neonatal sepsis (EONS) and LONS. There is no reliable Malaysian data on the serious pre-discharge morbidities in ELBW and VLBW infants.

There is evidence of microbial intra-uterine invasion in 25 to $40 \%$ of preterm births $[7,8]$ and 7 to $12 \%$ of preterm labour with intact membranes [9]. The polymerase chain reaction (PCR) technique using $16 \mathrm{~S}$ rDNA for identification of bacteria can demonstrate the prevalence of microbial invasion of amniotic fluid to be 30 to $50 \%$ higher than conventional culture-based method [10,11]. The amniotic fluid of preterm births can be colonised by the ascending vaginal microbes even if the amniotic membrane is intact [11] and from placenta microbiome linked to the hypothesised haematogenous spread from maternal oral microbiome [12,13].

Maternal chorioamnionitis (bacterial infection of the amniotic fluid) together with fetal systemic inflammatory response syndrome [14] has been linked with numerous morbidities in very preterm neonates. These morbidities include an increase of PVL/Cerebral palsy [15,16], IVH [17-19], ROP [20], NEC [18,21] and EONS [19,22,23]. Chorioamnionitis is protective of LONS [23] probably through hastening the immune maturation. Chorioamnionitis is not associated directly with mortality in preterm infants $[19,24]$ as the majority of the microbial invasion of the amniotic cavity are caused by low-virulence bacteria [11].

After birth, an early balanced gut microbiome is crucial to physiological functions and immune system maturation [25]. In recent year, burgeoning of evidence has also pointed out the significance of gut microbiome in providing colonization resistance against pathogens or opportunistic gut-derived pathobionts. The disruption of the maturation of bacterial gut microbiome, namely intestinal dysbacteriosis predisposes the neonates to NEC [26] and nosocomial infection or LONS [27-30]. The poor somatic growth of very preterm infants is related to a disrupted gut-brain axis [31], distorted gut microbiota composition [32,33], inadequate calorie intake [34] and existing neonatal morbidities. Although numerous studies support the notion that intestinal bacteria play an essential role in the pathogenesis of NEC, EONS and LONS, there has been no single bacterial species consistently identified as the causative agent. That said, several microorganisms have been implicated in NEC, primarily from the phyla Firmicutes (coagulase-negative staphylococci) and Proteobacteria (Cronobacter sakazakii, Klebsiella sp. and E. coli) $[35,36]$. Specifically, an increased abundance of Clostridium spp. and associated toxins has also been observed in the stool of neonates with NEC [37-39]. Acquisition of Group B Streptococcus (GBS) and E. coli during the birth process has been identified as the primary cause of EONS within 3 days postpartum among preterm infants [40]. Meanwhile, commensals of the skin or intestines, including Staphylococcus spp., E. coli, K. pneumoniae or Candida spp. are typically causing the LONS [41]. Thus, the pattern and magnitude of the bacterial gut disruption is an active ongoing research subject in preterm infants with adverse outcomes. This review aims to provide valuable insights into the gut bacteria in preterm neonates' meconium and stool, gut bacteria in NEC and LONS (Figure 1). 


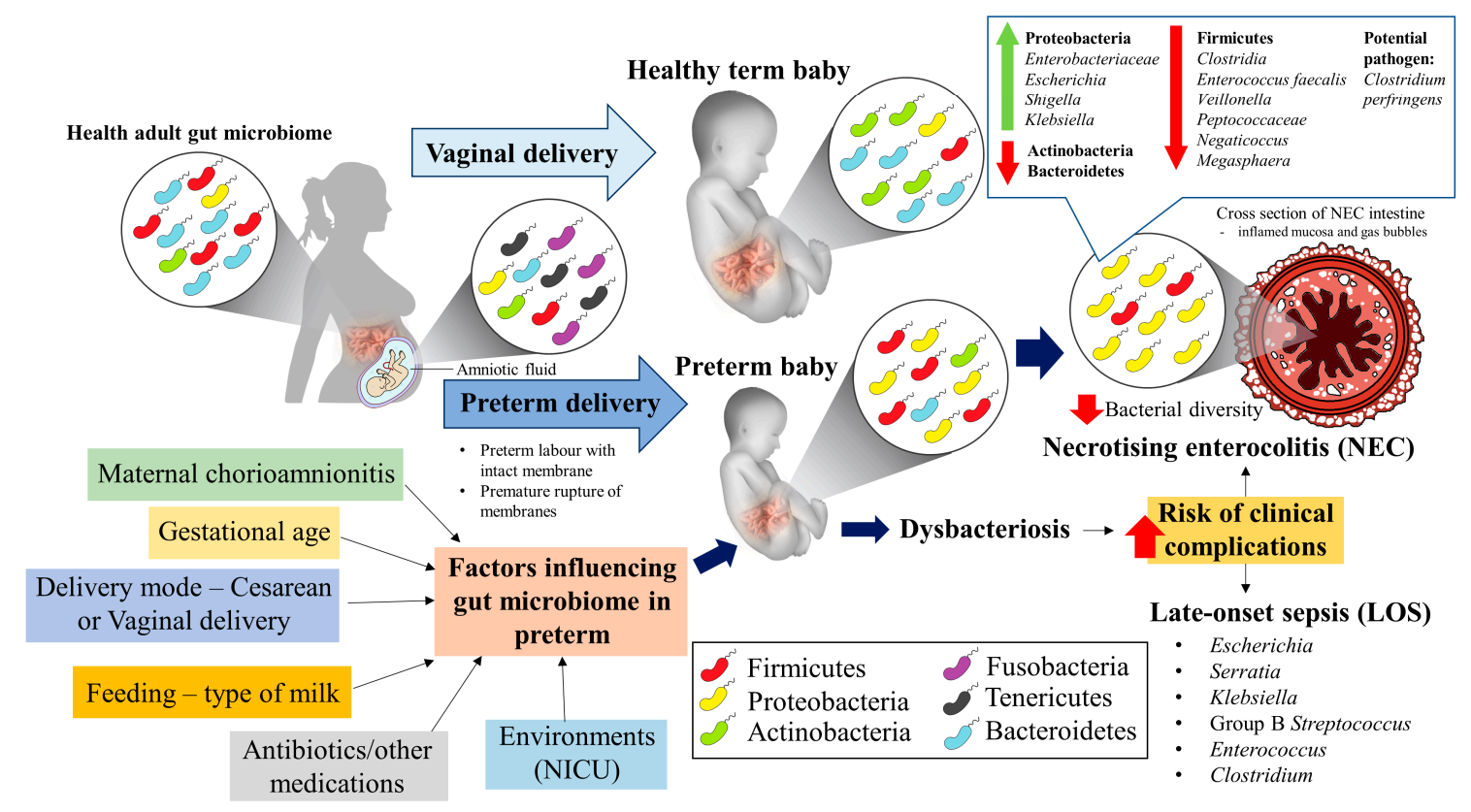

Figure 1. A graphical abstract illustrates the associations between the gut microbiome of preterm infants alone or in combination with postnatal gut dysbacteriosis and the predisposition to NEC and LONS.

\section{Gut Bacteria in Preterm Neonates-An Overview}

In the healthy adult gut, the dominant phyla of Bacteroidetes and Firmicutes make up $>90 \%$ of the microbiota [42]. The lesser phyla are Proteobacteria, Actinobacteria, Fusobacteria and Verrucomicrobia [43]. More than $99 \%$ of healthy gut microbes are anaerobes residing mainly in the distal ileum and colon. In comparison, the 4 main bacterial phyla present in the gut for both healthy neonate and preterm VLBW infant include Firmicutes, Proteobacteria, Actinobacteria and Bacteroidetes [44-48]. However, preterm and VLBW infants have lower microbial diversity, disrupted gut microbiome and increasing colonization of hospital acquired potentially pathogenic microorganisms when compared to age-matched full-term infants [49]. For instance, the GBS and Escherichia coli were the common cause of severe EOS and deaths in NICU [50,51].

Following birth, there are numerous factors which disrupt the initial gut bacteria colonisation and subsequent maturation of the preterm gut microbiome. Primarily, these factors include gestational age, mode of delivery (vaginal birth vs. Caesarean section), feeding methods (breast milk vs. formula) and early use of antibiotics [52,53]. For instance, Arboleya, et al. [47] demonstrated that preterm compared to term neonates have increased Enterococcus, Enterobacter, Lactobacillus, Staphylococcus and decreased Bacteroides, Bifidobacterium and Atopobium. Gut colonisation by Bifidobacterium has also shown to be delayed in preterm infants. A prospective study revealed that the gestational age has significant impact on gut colonization by bifidobacteria, whereby a birth at a gestational age $<33$ weeks seems to impair bifidobacterial colonization and predisposes preterm infants to gut infection and diseases [54].

\subsection{The Amniotic Fluid Is Colonised by Bacteria before Preterm Delivery}

The conventional view that human fetus is sterile has been challenged by the recent evidence showing the presence of microorganisms in normal healthy placenta, amniotic fluid and meconium [55-57]. Despite that, there are studies questioning on the existence of a normal placental microbiome, thereby suggesting that the detection of bacteria in the placental samples may be due to contamination acquired during delivery, sample processing and analysis [58-60]. Nevertheless, prenatal seeding of the human microbiome is expected to have significant implications on the pregnancy outcomes and subsequently the post-natal colonization events [55,61]. It is hypothesized that the in 
utero colonization could trigger immune activation or sensitization, resulting in production of immune mediators, thus affecting the immune system, gut and brain of the fetus $[55,61]$.

In contrary, the presence of pathogenic microorganisms in the intra-amniotic spaces has been well-known as the main driver for pro-inflammatory condition that can lead to adverse pregnancy outcomes like preterm birth and spontaneous death of fetus [62]. One of the major findings from a retrospective study revealed that a significant inverse association between the bacterial abundance in amniotic fluid and gestational age at delivery, thus supporting the contributory role for intra-uterine infection in preterm birth $[10,63]$. A systemic host inflammatory response induced possibly via oral periodontal disease and direct oral-utero transmission were the possible mechanisms suggested to enhance the adverse pregnancy outcomes [62].

Preterm parturition can occur with distinct clinical phenotypes, such as the preterm labor with intact membranes and preterm premature rupture of membranes (PROM). It has been long that microbial invasion of the amniotic cavity (MIAC) is associated with preterm PROM cases. PCR-based molecular studies identified that the predominant phyla in human gut microbiome Firmicutes, Bacteroidetes, Actinobacteria and Proteobacteria are present in the amniotic fluid during preterm labour $[10,11,64]$. Although at different relative proportions, the Fusobacteria and Tenericutes together made up slightly more than $50 \%$ of the bacteria in the amniotic fluid in both clinical scenario of preterm labour with intact membranes and preterm PROM [11]. Several specific genera from the phyla of Tenericutes (Ureaplasma and Mycoplasma) and Fusobacteria (Sneathia and Leptotrichia) were also suggested to appear as intra-amniotic pathogens due to their increased prevalence in cases of peripartum bacteremia [65,66]. Interestingly, a recent in vivo study established a causal link between Ureaplasma species and adverse pregnancy and neonatal outcomes, demonstrating that the intra-amniotic inoculation of clinically isolated Ureaplasma species induced preterm birth and neonatal mortality by causing severe inflammatory response in several reproductive organs of pregnant mice [67]. Taken together, these findings have indicated that the amniotic fluid from pregnant women who deliver prematurely, regardless of with intact or rupture membrane, is colonized with microorganisms.

\subsection{The Bacteria Present in the Meconium}

Generally, first-pass meconium samples are collected as a proxy for the bacterial communities in the in utero fetal gut environment. It is believed that meconium is a unique substance, consisting of bile acids, pancreatic secretions, epithelial cells, forming through the physiological process of in utero swallowing of amniotic fluid before birth [68]. Furthermore, meconium sample collection is simpler, more rapid and noninvasive when compared to the amniocentesis procedure of obtaining the amniotic fluid for the purpose of research investigations. That said, the analysis of meconium microbiome from infants can be essential to gain a better understanding of microbial establishment in human intestine as well as their potential role in infant health and disease.

Among preterm neonates, the gut bacteria present in meconium varies with gestation age. A study of 52 infants with gestation 23 to 41 weeks [69] revealed bacterial PCR was positive in $74 \%$ (of 35 infants) of neonates less than 33 weeks and 53\% (of 17 infants) more than 33 weeks gestation. The mean relative abundance and standard deviation for gestation less than 33 weeks was Firmicutes $44.5 \pm$ $17.6 \%$, Proteobacteria $35.4 \pm 17.9 \%$, Actinobacteria $7.6 \pm 7.6 \%$ and Bacteroidetes $6.0 \pm 8.0 \%$.

A similar pattern of bacteria phyla present in the meconium was demonstrated in 14 preterm neonates with gestation 24-31 weeks [70]. The most abundant phyla were Firmicutes $63.4 \%$ with $95 \% \mathrm{CI}$ 42.2-84.6, Proteobacteria $27.7 \%$ with 95\% CI 7.61-47.7 and Actinobacteria 3.5\% with 95\% CI 2.2-22.2. The main genera present in the meconium were Bacilli, Staphylococcus, Streptococcus, Enterococcus and Lactobacillus (all Firmicutes). The Shannon-Weaver diversity index of the meconium was 3.8 which increased to 4.0 for the stools at 3 weeks.

In a study on 23 neonates [71] showed that the Simpson diversity index of meconium in $<30$ weeks was a mean of 6.20 (sd 2.62) in 5 neonates compared to 8.56 (2.37) in 7 neonates for $>7$ days postnatal age. A longitudinal cohort study on 12 preterm with gestation $28.2 \pm 1.5$ weeks, birth weight 1055 
$\pm 234 \mathrm{~g}$ showed that the Shannon diversity 1.4 is lowest at birth, and Tenericutes was present in the meconium [72].

Collectively, there has been overarching agreement in the literature that the bacterial composition of meconium reflects the in utero microbial environment. Studies showed that large relative abundance of genera from meconium was shared with the amniotic fluid samples than from other microbial niches, indicating that the microbes from the meconium of the infants are not of postnatal origin [69,71]. In general, the meconium of preterm baby is predominated by Firmicutes and Proteobacteria as well as low species diversity when compared to term baby [70].

\subsection{The Maturation of the Gut Microbiome}

There are two conceptual models to the development of the preterm gut microbiome. The first concept is the gut microbiome develops in a structured pattern which is dependent on the host maturation with little influence from the environmental factors [73,74]. The second concept is the external factors such as diet [75], antibiotic exposure $[76,77]$ and hospital environment $[72,78]$ play a major role in the gut microbiome assembly.

A study by La Rosa, et al. [73] investigated on 58 preterm with median gestation 27.1 weeks and median birthweight 960 (IQR 800,1200) inclusive of 7 neonates with septicaemia, showed there were abrupt shifts of the gut bacteria classes but with nonrandom assembly pattern. The saltatory change progresses from the slow decrease of Bacilli (Firmicutes), while Gammaproteobacteria (Proteobacteria) bloomed and remained abundant, and followed by gradual increase of Clostridia (Firmicutes) in the gut microbiome. The proportion of Bacilli-Gammaproteobacteria-Clostridia in infancy was $19 \%-54 \%-18.5 \%$. Clostridia was well represented by $33-36$ weeks corrected age. Overall, the study suggested that the microbial population changes were mainly influenced by gestation at birth of the neonates.

Grier, et al. [74] showed a similar pattern with 95 preterm babies with gestation $28.8 \pm 3.4$ weeks and 25 term infants. The gut microbiota of subjects across postmenstrual age from 24 to 46 weeks were analysed. The relative abundance of the classes was Bacilli (Firmicutes) $41.8 \%$, Gammaproteobacteria (Proteobacteria) 23.0\%, Clostridia (Firmicutes) 22.5\%, Actinobacteria (Actinobacteria) $6.5 \%$ and Bacteroidia (Bacteroidetes) 5.1\%. There was a patterned progression with predominance of Bacilli (Firmicutes), Gammaproteobacteria (Proteobacteria) and Clostridia (Firmicutes) from gestational age 27 weeks to 30 weeks.

A study on 32 VLBW infants which included 3 NEC and 8 LONS and 21 healthy controls [76] supported the notion that the microbiome development was individualised and not influenced by NEC and LONS. Most stools were dominated by Enterobacteriaceae, Enterococcus, Staphylococcus and Bacteroides with reduction of Bifidobacterium and this reflected antibiotic use. One to 3 genera of bacteria dominated most stool samples. Each individual patient accounted for $48 \%$ $(p<0.001)$ of the variance in the stool samples from permutational multivariate analysis of variance (PERMANOVA) while the delivery mode accounted for $12 \%$ of the variance $(p<0.05)$.

\subsection{The Predominant Bacteria in the Early Stools}

The early colonisers are facultative anaerobes which will be replaced by the obligate anaerobes Bacteroides and Clostridia by 1 to 2 weeks of life. Chernikova, et al. [77] did a longitudinal study on weekly stools of 9 extremely preterm neonates with gestation 24-29 weeks. The facultative anaerobes Escherichia $(p=0.03)$ and Shigella $(p=0.027)$ decreased over time. Streptococcus $(p<0.001)$ and Enterococcus $(p=0.004)$ increased over time. Staphylococcus had the most significant decrease over time $(p=0.006)$ and Veillonella $(p<0.001)$ the most significant increase over time. The dominant genera were Enterobacter 19\%, Bacteroides 14\% and Staphylococcus $12 \%$. There was a paucity of Bifidobacterium $0.01 \%$ and Escherichia $0.17 \%$ in this cohort.

The cohort by Ho, et al. [79] on 45 VLBW infants with gestation $27.9 \pm 2.2$ weeks and birthweight $1126 \pm 208$ g showed a dichotomy of gut microbiome. A group started with low Gammaproteobacteria 
which increased with time with concomitant decreasing Firmicutes. The other group had high Gammaproteobacteria and low Firmicutes throughout. Meanwhile, Actinobacteria and Bacteroidetes were low throughout for both groups.

\subsection{Proportion of Bacteria and Bacterial Diversity in the First Month of Life in Preterm Infants}

Drell, et al. [80] studied 50 preterm with gestation 24-31 weeks, 2 died, 2 EONS, 2 LONS, 7 NEC stage $\geq 2$. The stool was collected at 1 week, 1 month and 2 months. The ELBW gut was dominated by facultative anaerobes and potential pathogens such as Staphylococcus and Enterobacteriaceae, and lacked the beneficial Bacteroides, Bifidobacterium and Lactobacillus. Proteobacteria had a prevalence of $94 \%$ and mean relative abundance $0.51(\mathrm{sd}=0.42)$. Its prevalence increased from $0.28(\mathrm{sd}=0.44)$ at 1 week to $0.66(\mathrm{sd}=0.39)$ at 1 month $(p<0.01)$. Firmicutes had a prevalence of $100 \%$ with mean relative abundance of $0.45(\mathrm{sd}=0.41)$. Its prevalence decreased from $0.65(\mathrm{sd}=0.45)$ at 1 week to 0.32 $(\mathrm{sd}=0.37)$ at 1 month $(p<0.01)$. The less dominant phyla were Bacteroidetes with prevalence $13 \%$ and relative abundance $0.02(\mathrm{sd}=0.14)$ and Actinobacteria with prevalence $13 \%$ and relative abundance 0.002 (sd = 0.07). The most prevalent genera at 1 week were Staphylococcus, Enterococcus and Klebsiella, while Escherichia, Shigella, Enterobacteriaceae and Enterococcus are dominant at 1 month. The average Shannon diversity index increased over time from mean $0.38(\mathrm{sd}=0.4)$ at 1 week, mean $0.71(\mathrm{sd}=0.54)$ at 1 month, and mean $0.92(\mathrm{sd}=0.44)$ at 2 months old $(p<0.01)$.

Patel, et al. [72] looked at 12 preterm gestation $28.2 \pm 1.5$ weeks, birthweight $1055 \pm 234 \mathrm{~g}$, inclusive of 1 NEC, 3 LONS. The rectal swab taken at birth and weekly showed a predominance of Enterobacteriaceae (Proteobacteria), Staphylococcaceae (Firmicutes) and Enterococcaceae (Firmicutes) with infrequent Lactobacillaceae and Bifidobacterium species. Enterobacteriaceae comprised 33\% of bacterial families in week 1 and increased to $53 \%$ by week 3 to $5(p=0.021)$. Enterobacteriaceae accounted for $60 \%$ of Proteobacteria in week 1,84\% in week 2 and $88 \%$ by week 3 to 5 . Proteobacteria comprised 55\% at week 1 and $59 \%$ by week 3 to 5 . At 1, 2, 3 weeks, Shannon was 1.4, 0.8, 0.9 and Chao1 was 15-18, 6-12, 7-11 respectively. The Shannon diversity was lowest at birth, increased by week 2 and declined rapidly by week 3 to $5(p<0.01)$.

In summary, the postnatal very preterm gut is colonised in a structured sequence by facultative anaerobes followed by obligate anaerobes. The initial class is Bacilli followed by a bloom of Gammaproteobacteria and finally an increase in Clostridia. There is a paucity of Lactobacillus, Bifidobacillus and the phyla Bacteroidetes and Actinobacteria. The final pattern is well established by 30 to 36 weeks corrected age. At phylum level, Firmicutes dominates at 1 week and Proteobacteria at 1 month. The prevalence of Firmicutes at 1 week is 0.65 decreasing to 0.32 by 1 month while Proteobacteria increases from 0.28 to 0.66 over the same period. The Shannon diversity index ranges from 0.38 to 1.4 at 1 week, increases by 2 weeks and reaches 0.71 to 0.9 by 1 month.

\section{Factors Influencing Gut Microbiome of Preterm Neonate}

The very preterm neonates are exposed to factors which alter the initial colonization and delay the maturation of the preterm gut microbiome. These factors include the bacteria causing chorioamnionitis and subsequently present in the meconium, the degree of prematurity, the delivery mode, delay and type of feeding, exposure to maternal and postnatal antibiotics and long stay in the neonatal wards.

\subsection{Maternal Chorioamnionitis and Bacteria Derived from First Meconium}

Puri, et al. [81] looked at the stools in the first 3 weeks in extremely preterm neonates with 32 chorioamnionitis, 26 chorioamnionitis with funisitis and 48 controls. Chorioamnionitis and chorioamnionitis-fusitis had higher LONS or death $(p=0.0033)$. Genus Sneathia and family Mycoplasmaceae were associated with higher risk of NEC, LONS or death $(p=0.01$, OR 5.5, 95\% CI 1.3, 21.0).

Chernikova, et al. [82] analysed the weekly stools of 9 extremely preterm with gestation 24-29 weeks, birthweight 510-1295 g, inclusive of 2 prolonged PPROM (pPPROM), 2 chorioamnionitis. 
pPPROM neonates had more Staphylococcus $(p=0.013)$ and Streptococcus $(p=0.033)$ and faster increase of Enterobacter $(p=0.009)$ and slower Clostridium $(p=0.02)$. Neonates with maternal chorioamnionitis showed faster increase of Serratia $(p<0.001)$ and Parabacteroides $(p=0.004)$.

For preterm neonates, there is one study on meconium [69] and numerous studies on meconium and stools $[47,70,72-75,77,83]$. None of these studies correlate the bacteria present in the meconium with the subsequent pattern of postnatal gut microbiome.

\subsection{Gestational Age}

La Rosa, et al. [73] stated that the rate of a structured maturation of gut microbiome was dependent on the gestation age at birth and postnatal age. The study by Chernikova, et al. [77] showed that the gestational age at birth had a significant influence on gut microbiome, and the Simpson index was 0.35 for extremely preterm versus 0.65 for very preterm neonates. Gregory, et al. [75] concurred that gestational age at birth drove the trajectory of microbiome development during the first 3 weeks of life. Drell, et al. [80] showed a positive correlation between Shannon index and corrected gestational age $(p<0.001)$.

\subsection{Delivery Mode}

The following studies on preterm neonates did not show any association between delivery mode and gut microbiome. Stewart, et al. [84] studied 25 spontaneous vaginal delivery (SVD) and 21 cesarean section (CS) preterm infants with gestation 24-31 weeks in the first 100 days of life. The birth mode was not associated with the relative abundance of genera, and both alpha (within) and beta (between) diversity. Grier, et al. [74] did a study on 95 preterm with gestation $28.8 \pm 3.4$ weeks and 25 term infants with 60 CS and 60 SVD. The delivery mode was not significantly associated with gut microbiome after controlling for age. In Patel, et al. [72] on 12 VLBW with gestation $28.2 \pm 1.5$ weeks, birth weight 1055 $\pm 234 \mathrm{~g}, 1 \mathrm{NEC}, 3$ LONS with $67 \%$ (8/12) CS, there was no association between mode of delivery and gut microbiome composition in VLBW infants managed in the NICU.

Several studies showed that the delivery mode in preterm neonates contributed to some differences in the gut microbiome. In Ho, et al. [79] on 45 VLBW infants with SVD 11/45 (24.4\%), Gammaproteobacteria was positively associated with SVD in $\leq 2$ weeks of life $(\mathrm{F}=9.55, p=$ $0.002)$ while Firmicutes was positively associated with CS $(\mathrm{F}=21.49, p<0.001)$. A study by Wandro, et al. [76] on preterm VLBW neonates showed that Bacteroides was found in 4/9 SVD and none of the 22 CS. The mode of delivery accounted for $12 \%$ variance of the bacterial composition. Similarly, the study by Arboleya, et al. [83] on 27 gestation 24-32 weeks, 7 SVD, 20 CS showed that SVD babies had more Bacteroides at 10 days of life $(p<0.05)$.

\subsection{Feeding-Type of Milk}

Gregory, et al. [75] studied 3 groups of 10 preterm $<32$ weeks gestation per group, of predominant maternal breast milk (MBM), pasteurised donor human milk (PDHM) or infant formula (IF). The preterm gut microbiome was influenced by birthweight $(p<0.001)$, postnatal age $(p<0.001)$ and types of feeding $(p<0.001)$. The gut was dominated by Bacillales (Firmicutes) and Lactobacillales (Firmicutes) until 28 to 30 weeks corrected age especially in IF fed ELBW infants. MBM had more Clostridia (Firmicutes) and Enterobacteriales (Proteobacteria). The succession in MBM infants was Bacillales, Lactobacillales, then Enterobacteriales, Clostridiales and Bifidobacteriales. IF had higher persistent Bacillales and Lactobacillales. In IF, Clostridiales was 10 times more in VLBW compared to ELBW infants. The Shannon diversity of MBM increased from 2.2 to 2.8 and for IF from 2.1 to 2.9.

La Rosa, et al. [73] studied 58 preterm with 15 gestation $<26$ weeks, 20 gestation $26-28$ weeks, 23 gestation $>28$ weeks. These neonates were fed on zero human milk $2(3.4 \%),<10 \%$ human milk $16(57.1 \%), 10-50 \%$ human milk $18(31.0 \%),>50 \%$ human milk $22(37.9 \%)$. Breast milk was associated with increased proportion of Gammaproteobacteria but not after 28 weeks gestation. 


\subsection{Antibiotics/Other Medications}

Although intrapartum antibiotic prophylaxis aims to prevent EOS, particularly GBS infection, in neonates, perinatal antibiotics influence the types of bacteria present and diversity of the preterm gut microbiome. Arboleya, et al. [83] did a retrospective cohort study on 27 neonates with gestation 24-32 weeks with 13 full-term, vaginally delivered, exclusively breast-fed (FTVDBF) controls. The perinatal antibiotics including intrapartum antimicrobial prophylaxis resulted in an increase of Enterobacteriaceae. Meanwhile, significantly higher abundance of Comamonadaceae (Proteobacteria), Staphylococcaceae (Firmicutes) and Bacilli (Firmicutes) $(p<0.05)$ was observed in infants without exposed to antibiotics. In another study by Arboleya, et al. [47] demonstrated that antibiotic administration significantly reduced the Bifidobacterium levels in preterm neonates at 10 days of life $(p<0.05)$, but not on other microbial groups tested.

A similar result is obtained by Chernikova, et al. [77] on 17 NICU infants with antibiotic use $94 \%, 13$ preterm, 176 term neonates. In premature infants, antibiotic use was associated with lower Bifidobacterium ( $p=0.015$ ) and Bacteroides ( $p=0.041)$. The study by La Rosa, et al. [73] on 58 preterm neonates with median percent 14 (IQR 5.8,25.6) days of life on antibiotics, showed that antibiotic use was associated with increased proportion of Gammaproteobacteria for gestation $\geq 26$ weeks and decreased Clostridia $\leq 28$ weeks.

Dardas, et al. [85] analysed the rectal swab at 10 and 30 days in 29 neonates with gestation 24-32 weeks and duration of antibiotics 2 days versus 7 days. The neonatal gut microbiome was affected by postnatal age and antibiotic exposure. Firmicutes and Bacteroidetes predominated the 10-day sample. There was a rise in Proteobacteria and Actinobacteria at 30 days. For those neonates who received 7-10 days versus 2 days antibiotics, there was a significantly reduced Shannon index from 10 days of life after adjustment for delivery mode.

Wandro, et al. [76] studied 32 VLBW neonates with 25 on antibiotics and 6 not on antibiotic and one unknown status. The preterm gut microbiome was influenced by antibiotics irrespective of the health outcomes of being 21 healthy, 8 LONS and 3 NEC. Antibiotic use was associated with lower Shannon diversity $(p=0.06)$.

\subsection{Environment}

Ho, et al. [79] studied 45 VLBW infants with gestation $27.9 \pm 2.2$ weeks over one month. There were two distinct clusters based on the abundance of Gammaproteobacteria during the first 2 weeks. One group of 20 neonates had decreasing Firmicutes and low Gammaproteobacterial which slowly increased with time. A second group of 25 neonates had high Gammaproteobacterial and low Firmicutes throughout. A single variant of Klebsiella dominated in the second group suggesting an environmental origin of the gut microbiome. The study suggested the dominance of Klebsiella could be due to the repeated exposure to the hospital environment among the women with high-risk pregnancies who had received inpatient care before giving birth [79].

Brooks, et al. [78] followed only 2 preterm gestion 26 and 28 weeks with faeces collected every 3 days for 1 month. One neonate had facultative anaerobes for 12 days before shift to obligate anaerobes. The second neonate had facultative anaerobes throughout. The dominant gut taxa are also present in room environment namely Staphylococcus epidermidis, K. pneumoniae, Bacteroides fragilis and E. coli. This suggested the environment was a source of the microbes in the premature gut. Brooks, et al. [86] did a metagenomic study on the microbes present in 50 preterm neonates and the environment of the NICU. The common strains present in the environment and gut were Staphylococcal epidermidis, Enterococcus faecalis, Pseudomonas aeruginosa and Klebsiella pneumoniae. These microbes were present in the environment before and after detection in the preterm gut.

Taft, et al. [87] studied preterm neonates $<29$ weeks with 33 LONS and 33 controls in 2 sites. The gut microbiome disruption before the LONS was depending on the postnatal age and site. This implied that the environmental microbiome had an influence on the gut microbiome. 


\section{Gut Bacteria in NEC}

NEC is a life-threatening intestinal disease with mortality as high as $30 \%$, affecting $5-10 \%$ of preterm infants [35]. It involves severe inflammation and necrosis of the intestines with features characteristic of pneumatosis intestinalis [88]. The risk and mortality of NEC increases with lower gestation age [89]. Despite extensive ongoing research, the exact role of the gut microbiome in the pathophysiology of NEC is still elusive. NEC may occur in the presence of gut dysbacteriosis with low bacterial diversity and one pathogen group dominates the disease process.

\subsection{The Pathogens Associated with NEC}

There are a few studies which seem to implicate a pathogen or group of pathogens causes NEC, but this finding is not replicated in other studies. de la Cochetiere, et al. [90] performed 16S rRNA studies on preterm $<30$ weeks gestation with 3 NEC and 9 controls. The stools were collected at 1 st day and weekly. Clostridium perfringens was detected in the first 2 weeks of life in 3 neonates who later developed NEC. The controls did not have Clostridium perfringens. On the other hand, Heida, et al. [91] investigated the bacterial invasion of 43 surgical NEC specimens compared to 43 age-matched controls. Using FISH probes technique, Enterobacteriaceae dominated the NEC specimens.

\subsection{Abundance of Proteobacteria and Low Abundance of Firmicutes Is Associated with NEC}

Several studies seem to indicate that NEC occurs when there is an abundance of Proteobacteria with concomitant reduction of Firmicutes. Warner, et al. [92] performed a nested case control within a cohort VLBW study of 46 NEC with 120 controls. There was an increased proportion of facultative anaerobic Gammaproteobacteia (Proteobacteria) $(p=0.0011)$ and decreased proportions of strict anaerobic Negativicutes (Firmicutes) $(p=0.0013)$ and Clostridia-Negativicutes (both Firmicutes) $(p=0.005)$ in NEC compared to controls. The Gammaproteobacteria comprised mainly Enterobacteriaceae, Escherichia, Shigella and Klebsiella. The Negativicutes were mainly Veillonella, Negaticoccus and Megasphaera.

Claud, et al. [26] studied the gut microbiome development in preterm 5 NEC (mean gestation 26.8 weeks) and 5 matched controls (mean gestation 26.4 weeks). Weekly stool samples were collected for 10 weeks. Three weeks before NEC, the cases had an increase of Proteobacteria and decrease of Firmicutes (especially Veillonella, Peptococcaceae). The controls did not have such disruption.

Mai, et al. [93] did a matched case-control nested in a cohort study with 9 NEC and 9 controls, gestation $\leq 32$ weeks, and birth weight $\leq 1250 \mathrm{~g}$. NEC had lower Actinobacteria and Bacteroidetes compared to controls. In the week before NEC, Proteobacteria increased from 36.2 to $70.9 \%$ (34\% increase) and Firmicutes decreased from 60.7 to $28.8 \%$ (32\% decrease). For the controls, there was no significant change in phyla over time.

In a study by Wang, et al. [94] on 10 NEC gestation 25-31 weeks versus 10 controls gestation 26-32 weeks, the stool sample at NEC diagnosis (average collection time $<1$ day after diagnosis) was analysed. The controls had 4 phyla, namely Firmicutes (relative abundance 57.8\%), Proteobacteria $(35.0 \%)$, Bacteroidetes $(2.5 \%)$ and Fusobacteria $(0.5 \%)$, unclassified bacteria $(4.3 \%)$. The NEC cases had only 2 phyla, namely, Proteobacteria $(90.8 \%)$, Firmicutes $(9.1 \%)$, unclassified bacteria $(0.16 \%)$. The NEC cases compared to controls had an increase in Proteobacteria and decrease in Firmicutes $(p<0.001)$.

\subsection{Abundance of Both Proteobacteria and Firmicutes Is Associated with NEC}

Torrazza, et al. [95] did a study on preterm neonates $\leq 32$ weeks with 18 NEC and 35 controls. The first meconium and then weekly stool samples were analysed. Two weeks before NEC, cases compared to controls had higher Proteobacteria $61 \%$ versus $19 \%$. One week before NEC, cases compared to controls had higher Actinobacteria 3\% versus $0.4 \%$ respectively. NEC neonates had lower Bifidobacteria and Bacteroidetes in the weeks preceding diagnosis. The proportion of Firmicutes (Clostridia, Lactobacilli) increased from 34\% from 2 weeks to $52 \%$ from 1 week, to $72 \%$ just before NEC compared to less increase of Firmicutes in controls. This increase in Firmicutes in cases was not seen in 
other studies described previously. There was no difference between cases and controls for within sample $\alpha$-diversity Chao 1 at 2 weeks, 1 week and 0 week before diagnosis.

Sim, et al. [96] studied 12 NEC with 44 controls in preterm neonates $<32$ weeks. Seven out of 11 NEC had abundance of Klebsiella (Proteobacteria) $(p=0.049)$ and 4/11 NEC had abundance of Clostridia (Firmicutes) $(p=0.006)$.

\subsection{Firmicutes Disruption Is Associated with NEC}

McMurtry, et al. [97] recruited 95 preterm neonates $\leq 1500$ g, gestation $\leq 34$ weeks with 21 NEC and 74 controls. Unlike other NEC publication, the researcher classified the 21 NEC cases into 8 mild, 7 severe, 6 lethal grades of NEC. The total NEC cases versus controls showed less of the following bacteria, namely Actinobacteria $(p=0.009)$, lower Clostridia $(p=0.004)$, Veillonella $(p=0.007)$ and Streptococcus ( $p=0.002)$. There was no difference in Bacilli and Gammaproteobacteria. The total NEC compared to controls has lower Chao1 $(p<0.0001)$ and Shannon's $(p=0.0002)$. Comparing the grades of NEC to controls, the average abundance of Clostridia was $12 \%$ in mild NEC, $3 \%$ in severe NEC and $0 \%$ in lethal NEC. The Clostridia abundance in lethal NEC was lower than mild NEC $(p=0.025)$. As for the 74 controls, $14(19 \%)$ lacked Clostridia while 12/21 (57\%) of total NEC lacked Clostridia ( $p=0.002)$. This study seemed to imply Clostridia (Firmicutes) was protective of NEC.

Stewart, et al. [98] studied 38 infants recruited by convenient sampling with median 27 weeks gestation and median birthweight $895 \mathrm{~g}$. Eight developed NEC (4 surgical) and 13 had LONS. First and weekly stools were obtained and analysed using standard culture method and $16 \mathrm{~S}$ technique. Standard culture showed the most common bacteria were Enterococcus faecalis $40 \%$ and coagulase negative staphylococci (CONS) 39\%. NEC versus healthy infants had more CONS (Firmicutes) $(45 \%$ versus $30 \%$ ) and less Enterococcus faecalis (Firmicutes) (31\% versus 57\%). Using $16 \mathrm{~S}$ technique, Enterococcus was associated with NEC and Staphylococcus with LONS.

\subsection{Association of Gut Dysbacteriosis with NEC}

The published studies do not support the concept that NEC consistently arises from the worst gut dysbacteriosis. Morrow, et al. [99] recruited preterm neonates $<29$ weeks gestation including 11 NEC with 21 matched controls. There were two distinct forms of dysbacteriosis prior to NEC. The NEC were either preceded by Firmicutes relative abundance $\geq 98 \%$ from day 4 to 9 or Proteobacteria (specifically Enterobacteriaceae) relative abundance $\geq 90 \%$ from days 10 to 16 days. The predictive value was $88 \%$ $(p<0.001)$ as only $25 \%$ of controls have this phenotype. All NEC cases lacked Propionibacterium (Actinobacterium).

Stewart, et al. [100] enrolled 318 preterm $<32$ weeks gestation of which had 7 NEC (median gestation 26 weeks (range 23-30 weeks)) matched with 28 controls (median gestation 27 weeks (range 24-30 weeks)). The dominant bacteria in all samples were Klebsiella, Escherichia, Staphylococcus and Enterococcus. There were 6 distinct clusters of preterm gut community types each dominated by Klebsiella, Klebsiella and Enterococcus, Staphylococcus, Enterococcus, Escherichia, mixed population with more Bifidobacterium. There was no causative pathogen detected in NEC, but more Bifidobacterium may protect against NEC.

Normann, et al. [101] studied 10 NEC with 16 matched controls in extremely low birthweight neonates. There was no difference in the weekly stool microbiome and bacterial diversity in patients developing NEC and controls. The predominant bacteria were Enterococcus (Firmicutes), Bacillales (Firmicutes) and Enterobacteriaceae (Proteobacteria). Prior to NEC, the cases had more Bacillales and Enterobacteriaceae and the controls had more Enterococcus (all were not statistically significant). In the 16 controls, the Enterococcus and Bacillales were succeeded by Enterobacteriaceae.

Mshvildadze, et al. [71] looked at 23 preterm neonates with gestation 23-32 weeks, birthweight 520-1997 g, inclusive of 6 NEC. The overall profiles in NEC were not distinguishable from controls. NEC showed an increase of Citrobacter-like (Proteobacteria) and Enterococcus-like (Firmicutes) sequences 
compared to controls. Controls had more frequent Klebsiella (Proteobacteria) $(p=0.06)$ and Enterobacteriaceae (Proteobacteria) $(p<0.05)$ which differed from other studies.

\subsection{Bacterial Diversity of NEC Versus Non-NEC Patients}

NEC seems to occur in preterm gut microbiome with lower bacterial diversity. Studies which show lower bacterial diversity are Wang, et al. [94], McMurtry, et al. [97] and Morrow, et al. [99]. In McMurtry, et al. [97], the median Shannon diversity in the 74 controls was 3.5 compared to 2.5 in the 21 NEC $(p<0.001)$. The difference was significant with mild $(p=0.01)$, severe $(p=0.03)$ and lethal $(p=$ 0.04) NEC, compared to controls. The relative lack of diversity in the infants developing NEC has been attributed to the fact that they were receiving more days of antibiotic therapy prior to manifestation of NEC when compared to normal infants [94].

Nevertheless, there were studies which do not show any difference, such as Mai, et al. [93], Torrazza, et al. [95] and Normann, et al. [101]. Pammi, et al. [35] did a meta-analysis on 8 studies with 106 NEC and 278 controls. The alpha Shannon 2.8 and beta Simpson 0.75 diversity indices were similar for NEC and controls.

In summary, majority of the study demonstrated that microbial dysbacteriosis preceding NEC in preterm infants. Furthermore, the association between the increase in abundance from the phylum Proteobacteria while decrease in Firmicutes and Bacteroidetes with the predisposition to NEC in preterm infants was well supported by a systematic review and meta-analysis based on sequence data collected from previous studies [35]. Even though that intestinal dysbacteriosis being the major factor in NEC pathogenesis, the specific role of the microorganisms and their interactions with host immune system is yet to be clearly elucidated. That said, the fact that higher relative abundance of Proteobacteria presents as a cause or consequence of NEC is still elusive. Considering that Proteobacteria are gram negative microbes possessing large quantities of lipopolysaccharide (LPS) on their cell walls, an immune interaction mediated by toll-like receptor (TLR) 4 induction has been proposed as a potential mechanism inducing NEC. In fact, over-expression of TLR4 is observed in premature infant gut that involved in maintaining the equilibrium between adequate inflammatory response and homeostasis [102]. Thus, together with underdeveloped adaptive immunity of preterm infants and an increase in Proteobacteria may trigger excessive pro-inflammatory response in preterm gut, causing intestinal injury and necrosis [103].

\section{Gut Bacteria in Late-Onset Neonatal Sepsis (LONS)}

Late-onset neonatal sepsis remains a serious complication of prematurity that occurs between day 7 and day 10 after birth [104]. In general, empiric antibiotics are given to pregnant women or preterm infants to reduce the risk of EOS. Paradoxically, gut microbiome is disrupted as a result of the antibiotic therapy, giving way to the expansion and dominance of opportunistic pathobionts in the premature infants, hence leading to LONS [105].

A few studies showed a change in gut microbiome pattern before LONS. Mai, et al. [30] did a nested case control study in preterm $\leq 32$ weeks with 10 LONS cases and 18 controls. The first meconium and weekly stools were analysed. The author postulated that there was a lack of normal gut microbiome rather than the presence of potential pathogens as a risk factor for LONS and NEC [72]. There was a delay in colonisation by Proteobacteria in the LONS cases. Two weeks before LONS, the cases had lower Proteobacteria $0.5 \%$ compared to $20 \%$ in controls. Just before LONS, the cases experienced a late bloom of Proteobacteria to $15 \%$ compared to a decrease to $9.8 \%$ in controls. There was a higher proportion of Firmicutes in LONS two weeks before the diagnosis. There was less Bifidobacteria in cases compared to controls.

Carl, et al. [28] studied 163 VLBW neonates which included 11 LONS cases. The bacteria causing septicaemia were GBS $\times 4$, Serratia marcescens $\times 2$, Escherichia coli $\times 2$, Klebsiella pneumoniae $\times 1$, MRSA $\times 2$. Seven out of $11(64 \%)$ neonates had GBS $\times 3$, S. marcescens $\times 2$, E. coli $\times 2$ in their stool before their septicaemia. The common origin of the matched faecal and blood isolates was confirmed by genomic 
sequencing. The E. coli appeared earlier in the stool while the GBS and S. marcescens were detected closer to the septicaemia.

Shaw, et al. [29] studied preterm neonates with gestation $<32$ weeks with 22 LONS and 44 matched controls and daily faecal samples were collected. The most abundant OTUs (90\%) in faeces closest to the time of LONS were Klebsiella, Escherichia, Staphylococcus, Enterococcus and Clostridium. Enterobacteriaceal and staphylococcal LONS were associated with the bacterial OTUs in their stools.

Taft, et al. [87] studied preterm neonates $<29$ weeks in 2 sites. There were 13 and 20 LONS cases plus same number of controls in the 2 sites (NICU). The gut microbiome disruption occurred before the LONS, but the distortion depended on postnatal age and the site. Bacterial sequencing could detect the sepsis-causative organism in the stool in $82 \%$ of LONS.

To sum up, several gram-positive and gram-negative enteric bacteria have been identified as the major pathobionts causing LONS in preterm infants, including Klebsiella spp., E. coli and Serratia spp. (Gram-negative) and the Streptococcus spp., Enterococcus spp. and CONS. Furthermore, the LONS has also been associated with perturbed preterm gut microbiome, with lower bacterial diversity, higher abundance of Proteobacteria and Firmicutes but low in Bifidobacteria. Interestingly, these causative microorganisms were shown to be intestinal origin rather than microbial translocation from the skin as demonstrated by stool sampling from LONS cases.

\section{Conclusions}

Gut microbiome has been reported to be associated with various human diseases [106-111]. The pattern and magnitude of the bacterial gut disruption is an active ongoing research subject in preterm infants with adverse outcomes. However, there is still a wide knowledge gap on how the presence of gut bacteria at birth either alone or in combination with early postnatal gut dysbacteriosis interact to contribute to the mortality and severe pre-discharge morbidities of very preterm infants. In particular, the mechanistic information on how specific microbiota patterns might lead to NEC or LONS in preterm infants is still lacking. Thus, an improved understanding of the diversity of microbes causing NEC and LONS may propel forward important research regarding their sources, pathogenic mechanisms, microbiome-host interactions and clinical implications. Perhaps, different strategies of altering the neonatal microbiome to promote favorable microbial profile may prevent NEC and LONS in the high-risk preterm neonates. Furthermore, continued research into the empiric antibiotic usage in NICU is recommended in order to have a better-informed antibiotic selection in clinical practice. Therefore, these potential insights will be important for developing improved prevention, diagnostic and treatment strategies for NEC and LONS.

Author Contributions: The literature search and data collection were performed by J.K.-F.L. The manuscript was written by J.K.-F.L. and L.T.H.T. The manuscript was critically reviewed and edited by J.K.-F.L., L.T.H.T., A.R., N.-S.A.M. and L.-H.L. L.-H.L. provided vital guidance and insight to the work. The project was conceptualized by L.-H.L. and J.K.-F.L. All authors have read and agreed to the published version of the manuscript.

Funding: This research was funded by Seed Funding from Microbiome and Bioresource Research Strength (MBRS), Jeffrey Cheah School of Medicine and Health Sciences (JCSMHS) (Vote Number: MBRS/JCSMHS/01/2020).

Acknowledgments: Authors would like to acknowledge the support from Shajahan Yasin, Head of School, Jeffrey Cheah School of Medicine and Health Sciences, Monash University Malaysia that enabled the success of the project.

Conflicts of Interest: The authors declare no conflict of interest.

\section{References}

1. Wang, H.; Bhutta, Z.A.; Coates, M.M.; Coggeshall, M.; Dandona, L.; Diallo, K.; Franca, E.B.; Fraser, M.; Fullman, N.; Gething, P.W.; et al. Global, regional, national, and selected subnational levels of stillbirths, neonatal, infant, and under-5 mortality, 1980-2015: A systematic analysis for the Global Burden of Disease Study 2015. Lancet 2016, 388, 1725-1774. [CrossRef] 
2. Blencowe, H.; Cousens, S.; Oestergaard, M.Z.; Chou, D.; Moller, A.-B.; Narwal, R.; Adler, A.; Vera Garcia, C.; Rohde, S.; Say, L.; et al. National, regional, and worldwide estimates of preterm birth rates in the year 2010 with time trends since 1990 for selected countries: A systematic analysis and implications. Lancet 2012, 379, 2162-2172. [CrossRef]

3. Gladstone, M.; Oliver, C.; Van den Broek, N. Survival, morbidity, growth and developmental delay for babies born preterm in low and middle income countries-A systematic review of outcomes measured. PLoS ONE 2015, 10, e0120566. [CrossRef]

4. Saigal, S.; Doyle, L.W. An overview of mortality and sequelae of preterm birth from infancy to adulthood. Lancet 2008, 371, 261-269. [CrossRef]

5. Malaysian National Neonatal Registry (MNNR). Report of the Malaysian National Neonatal Registry Annual Report 2015; Ministry of Health Malaysia: Kuala Lumpur, Malaysia, 2015. Available online: http://www. acrm.org.my/mnnr/documents/MNNR_Full_Report_2015.pdf (accessed on 22 September 2020).

6. Canadian Neonatal Network (CNN). The Canadian Neonatal Network Annual Report 2015; CNN: Toronto, ON, USA, 2015.

7. Lahra, M.M.; Beeby, P.J.; Jeffery, H.E. Maternal versus fetal inflammation and respiratory distress syndrome: A 10-year hospital cohort study. Arch. Dis. Child. Fetal Neonatal Ed. 2009, 94, F13-F16. [CrossRef]

8. Epstein, F.H.; Goldenberg, R.L.; Hauth, J.C.; Andrews, W.W. Intrauterine Infection and Preterm Delivery. N. Engl. J. Med. 2000, 342, 1500-1507. [CrossRef]

9. Romero, R.; Miranda, J.; Chaiworapongsa, T.; Chaemsaithong, P.; Gotsch, F.; Dong, Z.; Ahmed, A.I.; Yoon, B.H.; Hassan, S.S.; Kim, C.J.; et al. A novel molecular microbiologic technique for the rapid diagnosis of microbial invasion of the amniotic cavity and intra-amniotic infection in preterm labor with intact membranes. Am. J. Reprod Immunol. 2014, 71, 330-358. [CrossRef]

10. DiGiulio, D.B.; Romero, R.; Amogan, H.P.; Kusanovic, J.P.; Bik, E.M.; Gotsch, F.; Kim, C.J.; Erez, O.; Edwin, S.; Relman, D.A. Microbial prevalence, diversity and abundance in amniotic fluid during preterm labor: A molecular and culture-based investigation. PLOS ONE 2008, 3, e3056. [CrossRef]

11. DiGiulio, D.B. Diversity of microbes in amniotic fluid. Semin. Fetal Neonatal Med. 2012, 17, 2-11. [CrossRef]

12. Aagaard, K.; Ma, J.; Antony, K.M.; Ganu, R.; Petrosino, J.; Versalovic, J. The placenta harbors a unique microbiome. Sci. Transl. Med. 2014, 6, 237ra65. [CrossRef]

13. Leon, R.; Silva, N.; Ovalle, A.; Chaparro, A.; Ahumada, A.; Gajardo, M.; Martinez, M.; Gamonal, J. Detection of Porphyromonas gingivalis in the amniotic fluid in pregnant women with a diagnosis of threatened premature labor. J. Periodontol. 2007, 78, 1249-1255. [CrossRef]

14. Gantert, M.; Been, J.V.; Gavilanes, A.W.; Garnier, Y.; Zimmermann, L.J.; Kramer, B.W. Chorioamnionitis: A multiorgan disease of the fetus? J. Perinatol. 2010, 30 (Suppl. S1), S21-S30. [CrossRef] [PubMed]

15. Wu, Y.W.; Colford, J.J.M. Chorioamnionitis as a Risk Factor for Cerebral Palsy: A Meta-analysis. JAMA 2000, 284, 1417-1424. [CrossRef]

16. Shatrov, J.G.; Birch, S.C.M.; Lam, L.T.; Quinlivan, J.A.; McIntyre, S.; Mendz, G.L. Chorioamnionitis and Cerebral Palsy: A Meta-Analysis. Obstet. Gynecol. 2010, 116, 387-392. [CrossRef] [PubMed]

17. Ogunyemi, D.; Murillo, M.; Jackson, U.; Hunter, N.; Alperson, B. The relationship between placental histopathology findings and perinatal outcome in preterm infants. J. Matern. Fetal Neonatal Med. 2003, 13, 102-109. [CrossRef] [PubMed]

18. Andrews, W.W.; Goldenberg, R.L.; Faye-Petersen, O.; Cliver, S.; Goepfert, A.R.; Hauth, J.C. The Alabama Preterm Birth study: Polymorphonuclear and mononuclear cell placental infiltrations, other markers of inflammation, and outcomes in 23- to 32-week preterm newborn infants. Am. J. Obstet. Gynecol. 2006, 195, 803-808. [CrossRef]

19. Soraisham, A.S.; Singhal, N.; McMillan, D.D.; Sauve, R.S.; Lee, S.K.; Canadian Neonatal, N. A multicenter study on the clinical outcome of chorioamnionitis in preterm infants. Am. J. Obstet. Gynecol. 2009, 200, e371-e376. [CrossRef]

20. Dammann, O.; Brinkhaus, M.J.; Bartels, D.B.; Dordelmann, M.; Dressler, F.; Kerk, J.; Dork, T.; Dammann, C.E. Immaturity, perinatal inflammation, and retinopathy of prematurity: A multi-hit hypothesis. Early Hum. Dev. 2009, 85, 325-329. [CrossRef]

21. Been, J.V.; Lievense, S.; Zimmermann, L.J.; Kramer, B.W.; Wolfs, T.G. Chorioamnionitis as a risk factor for necrotizing enterocolitis: A systematic review and meta-analysis. J. Pediatr. 2013, 162, 236-242. [CrossRef] 
22. Klinger, G.; Levy, I.; Sirota, L.; Boyko, V.; Reichman, B.; Lerner-Geva, L.; Israel Neonatal, N. Epidemiology and risk factors for early onset sepsis among very-low-birthweight infants. Am. J. Obstet. Gynecol. 2009, 201, 38.e1-38.e6. [CrossRef]

23. Strunk, T.; Doherty, D.; Jacques, A.; Simmer, K.; Richmond, P.; Kohan, R.; Charles, A.; Burgner, D. Histologic chorioamnionitis is associated with reduced risk of late-onset sepsis in preterm infants. Pediatrics 2012, 129, e134-e141. [CrossRef] [PubMed]

24. Venkatesh, K.K.; Jackson, W.; Hughes, B.L.; Laughon, M.M.; Thorp, J.M.; Stamilio, D.M. Association of chorioamnionitis and its duration with neonatal morbidity and mortality. J. Perinatol. 2019, 39, 673-682. [CrossRef] [PubMed]

25. Staude, B.; Oehmke, F.; Lauer, T.; Behnke, J.; Gopel, W.; Schloter, M.; Schulz, H.; Krauss-Etschmann, S.; Ehrhardt, H. The Microbiome and Preterm Birth: A Change in Paradigm with Profound Implications for Pathophysiologic Concepts and Novel Therapeutic Strategies. Biomed Res. Int. 2018, 2018, 7218187. [CrossRef] [PubMed]

26. Claud, E.C.; Keegan, K.P.; Brulc, J.M.; Lu, L.; Bartels, D.; Glass, E.; Chang, E.B.; Meyer, F.; Antonopoulos, D.A. Bacterial community structure and functional contributions to emergence of health or necrotizing enterocolitis in preterm infants.(Report). Microbiome 2013, 1, 20. [CrossRef]

27. Madan, J.C.; Salari, R.C.; Saxena, D.; Davidson, L.; O’Toole, G.A.; Moore, J.H.; Sogin, M.L.; Foster, J.A.; Edwards, W.H.; Palumbo, P.; et al. Gut microbial colonisation in premature neonates predicts neonatal sepsis. Arch. Dis. Child. Fetal Neonatal Ed. 2012, 97, F456-F462. [CrossRef]

28. Carl, M.A.; Ndao, I.M.; Springman, A.C.; Manning, S.D.; Johnson, J.R.; Johnston, B.D.; Burnham, C.A.; Weinstock, E.S.; Weinstock, G.M.; Wylie, T.N.; et al. Sepsis from the gut: The enteric habitat of bacteria that cause late-onset neonatal bloodstream infections. Clin. Infect. Dis. 2014, 58, 1211-1218. [CrossRef]

29. Shaw, A.G.; Sim, K.; Randell, P.; Cox, M.J.; McClure, Z.E.; Li, M.S.; Donaldson, H.; Langford, P.R.; Cookson, W.O.; Moffatt, M.F.; et al. Late-Onset Bloodstream Infection and Perturbed Maturation of the Gastrointestinal Microbiota in Premature Infants. PLoS ONE 2015, 10, e0132923. [CrossRef]

30. Mai, V.; Torrazza, R.M.; Ukhanova, M.; Wang, X.; Sun, Y.; Li, N.; Shuster, J.; Sharma, R.; Hudak, M.L.; Neu, J. Distortions in development of intestinal microbiota associated with late onset sepsis in preterm infants. PLOS ONE 2013, 8, e52876. [CrossRef]

31. Groer, M.; Luciano, A.A.; Dishaw, L.; Ashmeade, T.; Miller, E.; Gilbert, J. Development of the preterm infant gut microbiome: A research priority. Microbiome 2014, 2, 38. [CrossRef]

32. Younge, N.E.; Newgard, C.B.; Cotten, C.M.; Goldberg, R.N.; Muehlbauer, M.J.; Bain, J.R.; Stevens, R.D.; O'Connell, T.M.; Rawls, J.F.; Seed, P.C.; et al. Disrupted Maturation of the Microbiota and Metabolome among Extremely Preterm Infants with Postnatal Growth Failure. Sci. Rep. 2019, 9, 8167. [CrossRef]

33. Henderickx, J.G.E.; Zwittink, R.D.; van Lingen, R.A.; Knol, J.; Belzer, C. The Preterm Gut Microbiota: An Inconspicuous Challenge in Nutritional Neonatal Care. Front. Cell. Infect. Microbiol. 2019, 9, 85. [CrossRef] [PubMed]

34. Lee, J.K.; Yu, V.Y. Calorie intake in sick versus respiratory stable very low birthweight babies. Pediatr. Int. 1996, 38, 449-454. [CrossRef] [PubMed]

35. Pammi, M.; Cope, J.; Tarr, P.I.; Warner, B.B.; Morrow, A.L.; Mai, V.; Gregory, K.E.; Kroll, J.S.; McMurtry, V.; Ferris, M.J.; et al. Intestinal dysbiosis in preterm infants preceding necrotizing enterocolitis: A systematic review and meta-analysis. Microbiome 2017, 5, 31. [CrossRef]

36. Coggins, S.A.; Wynn, J.L.; Weitkamp, J.-H. Infectious causes of necrotizing enterocolitis. Clin. Perinatol. 2015, 42, 133-154. [CrossRef]

37. Kosloske, A.M.; Ulrich, J.A. A bacteriologic basis for the clinical presentations of necrotizing enterocolitis. J. Pediatr. Surg. 1980, 15, 558-564. [PubMed]

38. Kosloske, A.; Ulrich, J.; Hoffman, H. Fulminant necrotising enterocolitis associated with clostridia. Lancet 1978, 312, 1014-1016.

39. Lindberg, T.P.; Caimano, M.J.; Hagadorn, J.I.; Bennett, E.M.; Maas, K.; Brownell, E.A.; Matson, A.P. Preterm infant gut microbial patterns related to the development of necrotizing enterocolitis. J. Matern.-Fetal Neonatal Med. 2020, 33, 349-358. [CrossRef]

40. Stoll, B.J.; Hansen, N.I.; Sánchez, P.J.; Faix, R.G.; Poindexter, B.B.; Van Meurs, K.P.; Bizzarro, M.J.; Goldberg, R.N.; Frantz, I.D.; Hale, E.C.; et al. Early Onset Neonatal Sepsis: The Burden of Group B Streptococcal and E. coli Disease Continues. Pediatrics 2011, 127, 817-826. [CrossRef] 
41. Dong, Y.; Speer, C.P. Late-onset neonatal sepsis: Recent developments. Arch. Dis. Child.-Fetal Neonatal Ed. 2015, 100, F257-F263.

42. Rinninella, E.; Raoul, P.; Cintoni, M.; Franceschi, F.; Miggiano, G.A.D.; Gasbarrini, A.; Mele, M.C. What is the Healthy Gut Microbiota Composition? A Changing Ecosystem across Age, Environment, Diet, and Diseases. Microorganisms 2019, 7, 14. [CrossRef]

43. Eckburg, P.B.; Bik, E.M.; Bernstein, C.N.; Purdom, E.; Dethlefsen, L.; Sargent, M.; Gill, S.R.; Nelson, K.E.; Relman, D.A. Diversity of the human intestinal microbial flora. Science 2005, 308, 1635. [CrossRef] [PubMed]

44. Adlerberth, I.; Wold, A.E. Establishment of the gut microbiota in Western infants. Acta Paediatr. 2009, 98, 229-238. [CrossRef] [PubMed]

45. Gritz, E.C.; Bhandari, V. The human neonatal gut microbiome: A brief review. Front. Pediatr. 2015, 3, 17. [CrossRef] [PubMed]

46. Unger, S.; Stintzi, A.; Shah, P.; Mack, D.; O'Connor, D.L. Gut microbiota of the very-low-birth-weight infant. Pediatr. Res. 2015, 77, 205-213. [CrossRef]

47. Arboleya, S.; Binetti, A.; Salazar, N.; Fernandez, N.; Solis, G.; Hernandez-Barranco, A.; Margolles, A.; de Los Reyes-Gavilan, C.G.; Gueimonde, M. Establishment and development of intestinal microbiota in preterm neonates. FEMS Microbiol. Ecol. 2012, 79, 763-772. [CrossRef] [PubMed]

48. Bjorkstrom, M.V.; Hall, L.; Soderlund, S.; Hakansson, E.G.; Hakansson, S.; Domellof, M. Intestinal flora in very low-birth weight infants. Acta Paediatr. 2009, 98, 1762-1767. [CrossRef]

49. Costello, E.K.; Carlisle, E.M.; Bik, E.M.; Morowitz, M.J.; Relman, D.A. Microbiome assembly across multiple body sites in low-birthweight infants. mBio 2013, 4. [CrossRef]

50. Tiskumara, R.; Fakharee, S.H.; Liu, C.Q.; Nuntnarumit, P.; Lui, K.M.; Hammoud, M.; Lee, J.K.; Chow, C.B.; Shenoi, A.; Halliday, R.; et al. Neonatal infections in Asia. Arch. Dis. Child. Fetal Neonatal Ed. 2009, 94, F144-F148. [CrossRef]

51. Al-Taiar, A.; Hammoud, M.S.; Cuiqing, L.; Lee, J.K.; Lui, K.M.; Nakwan, N.; Isaacs, D. Neonatal infections in China, Malaysia, Hong Kong and Thailand. Arch. Dis. Child. Fetal Neonatal Ed. 2013, 98, F249-F255. [CrossRef]

52. Marques, T.M.; Wall, R.; Ross, R.P.; Fitzgerald, G.F.; Ryan, C.A.; Stanton, C. Programming infant gut microbiota: Influence of dietary and environmental factors. Curr. Opin. Biotechnol. 2010, 21, 149-156. [CrossRef]

53. RodrÍguez, J.M.; Murphy, K.; Stanton, C.; Ross, R.P.; Kober, O.I.; Juge, N.; Avershina, E.; Rudi, K.; Narbad, A.; Jenmalm, M.C.; et al. The composition of the gut microbiota throughout life, with an emphasis on early life. Microb. Ecol. Health Dis. 2015, 26, 26050. [CrossRef] [PubMed]

54. Butel, M.-J.; Suau, A.; Campeotto, F.; Magne, F.; Aires, J.; Ferraris, L.; Kalach, N.; Leroux, B.; Dupont, C. Conditions of Bifidobacterial Colonization in Preterm Infants: A Prospective Analysis. J. Pediatr. Gastroenterol. Nutr. 2007, 44, 577-582. [CrossRef] [PubMed]

55. Stinson, L.F.; Boyce, M.C.; Payne, M.S.; Keelan, J.A. The Not-so-Sterile Womb: Evidence That the Human Fetus Is Exposed to Bacteria Prior to Birth. Front. Microbiol. 2019, 10, 1124. [CrossRef]

56. Parnell, L.A.; Briggs, C.M.; Cao, B.; Delannoy-Bruno, O.; Schrieffer, A.E.; Mysorekar, I.U. Microbial communities in placentas from term normal pregnancy exhibit spatially variable profiles. Sci. Rep. 2017, 7, 1-11. [CrossRef]

57. Collado, M.C.; Rautava, S.; Aakko, J.; Isolauri, E.; Salminen, S. Human gut colonisation may be initiated in utero by distinct microbial communities in the placenta and amniotic fluid. Sci. Rep. 2016, 6, 23129. [CrossRef] [PubMed]

58. Leiby, J.S.; McCormick, K.; Sherrill-Mix, S.; Clarke, E.L.; Kessler, L.R.; Taylor, L.J.; Hofstaedter, C.E.; Roche, A.M.; Mattei, L.M.; Bittinger, K.; et al. Lack of detection of a human placenta microbiome in samples from preterm and term deliveries. Microbiome 2018, 6, 196. [CrossRef] [PubMed]

59. Theis, K.R.; Romero, R.; Winters, A.D.; Greenberg, J.M.; Gomez-Lopez, N.; Alhousseini, A.; Bieda, J.; Maymon, E.; Pacora, P.; Fettweis, J.M.; et al. Does the human placenta delivered at term have a microbiota? Results of cultivation, quantitative real-time PCR, 16S rRNA gene sequencing, and metagenomics. Am. J. Obstet. Gynecol. 2019, 220, 267.e1-267.e39. [CrossRef]

60. Lim, E.S.; Rodriguez, C.; Holtz, L.R. Amniotic fluid from healthy term pregnancies does not harbor a detectable microbial community. Microbiome 2018, 6, 87. [CrossRef] 
61. Gil, A.; Rueda, R.; Ozanne, S.E.; van der Beek, E.M.; van Loo-Bouwman, C.; Schoemaker, M.; Marinello, V.; Venema, K.; Stanton, C.; Schelkle, B.; et al. Is there evidence for bacterial transfer via the placenta and any role in the colonization of the infant gut-A systematic review. Crit. Rev. Microbiol. 2020, 1-15. [CrossRef]

62. Figuero, E.; Han, Y.W.; Furuichi, Y. Periodontal diseases and adverse pregnancy outcomes: Mechanisms. Periodontology 2000 2020, 83, 175-188. [CrossRef]

63. Watts, D.H.; Krohn, M.A.; Hillier, S.L.; Eschenbach, D.A. The association of occult amniotic fluid infection with gestational age and neonatal outcome among women in preterm labor. Obstet. Gynecol. 1992, 79, 351-357. [CrossRef] [PubMed]

64. DiGiulio, D.B.; Romero, R.; Kusanovic, J.P.; Gomez, R.; Kim, C.J.; Seok, K.S.; Gotsch, F.; Mazaki-Tovi, S.; Vaisbuch, E.; Sanders, K.; et al. Prevalence and diversity of microbes in the amniotic fluid, the fetal inflammatory response, and pregnancy outcome in women with preterm pre-labor rupture of membranes. Am. J. Reprod Immunol. 2010, 64, 38-57. [CrossRef] [PubMed]

65. De Martino, S.J.; Mahoudeau, I.; Brettes, J.P.; Piemont, Y.; Monteil, H.; Jaulhac, B. Peripartum bacteremias due to Leptotrichia amnionii and Sneathia sanguinegens, rare causes of fever during and after delivery. J. Clin. Microbiol. 2004, 42, 5940-5943. [CrossRef]

66. Oh, K.J.; Romero, R.; Park, J.Y.; Hong, J.-S.; Yoon, B.H. The earlier the gestational age, the greater the intensity of the intra-amniotic inflammatory response in women with preterm premature rupture of membranes and amniotic fluid infection by Ureaplasma species. J. Perinat. Med. 2019, 47, 516-527. [CrossRef]

67. Motomura, K.; Romero, R.; Xu, Y.; Theis, K.R.; Galaz, J.; Winters, A.D.; Slutsky, R.; Garcia-Flores, V.; Zou, C.; Levenson, D.; et al. Intra-Amniotic Infection with Ureaplasma parvum Causes Preterm Birth and Neonatal Mortality That Are Prevented by Treatment with Clarithromycin. mBio 2020, 11, e00797-20. [CrossRef] [PubMed]

68. Stinson, L.F.; Keelan, J.A.; Payne, M.S. Comparison of Meconium DNA Extraction Methods for Use in Microbiome Studies. Front. Microbiol. 2018, 9, 270. [CrossRef] [PubMed]

69. Ardissone, A.N.; de la Cruz, D.M.; Davis-Richardson, A.G.; Rechcigl, K.T.; Li, N.; Drew, J.C.; Murgas-Torrazza, R.; Sharma, R.; Hudak, M.L.; Triplett, E.W.; et al. Meconium microbiome analysis identifies bacteria correlated with premature birth. PLoS ONE 2014, 9, e90784. [CrossRef]

70. Moles, L.; Gomez, M.; Heilig, H.; Bustos, G.; Fuentes, S.; de Vos, W.; Fernandez, L.; Rodriguez, J.M.; Jimenez, E. Bacterial diversity in meconium of preterm neonates and evolution of their fecal microbiota during the first month of life. PLoS ONE 2013, 8, e66986. [CrossRef]

71. Mshvildadze, M.; Neu, J.; Shuster, J.; Theriaque, D.; Li, N.; Mai, V. Intestinal microbial ecology in premature infants assessed with non-culture-based techniques. J. Pediatr. 2010, 156, 20-25. [CrossRef]

72. Patel, A.L.; Mutlu, E.A.; Sun, Y.; Koenig, L.; Green, S.; Jakubowicz, A.; Mryan, J.; Engen, P.; Fogg, L.; Chen, A.L.; et al. Longitudinal Survey of Microbiota in Hospitalized Preterm Very-Low-Birth-Weight Infants. J. Pediatric Gastroenterol. Nutr. 2016, 62, 292-303. [CrossRef]

73. La Rosa, P.S.; Warner, B.B.; Zhou, Y.; Weinstock, G.M.; Sodergren, E.; Hall-Moore, C.M.; Stevens, H.J.; Bennett, W.E., Jr.; Shaikh, N.; Linneman, L.A.; et al. Patterned progression of bacterial populations in the premature infant gut. Proc. Natl. Acad. Sci. USA 2014, 111, 12522-12527. [CrossRef] [PubMed]

74. Grier, A.; Qiu, X.; Bandyopadhyay, S.; Holden-Wiltse, J.; Kessler, H.A.; Gill, A.L.; Hamilton, B.; Huyck, H.; Misra, S.; Mariani, T.J.; et al. Impact of prematurity and nutrition on the developing gut microbiome and preterm infant growth. Microbiome 2017, 5, 158. [CrossRef] [PubMed]

75. Gregory, K.E.; Samuel, B.S.; Houghteling, P.; Shan, G.; Ausubel, F.M.; Sadreyev, R.I.; Walker, W.A. Influence of maternal breast milk ingestion on acquisition of the intestinal microbiome in preterm infants. Microbiome 2016, 4, 68. [CrossRef]

76. Wandro, S.; Osborne, S.; Enriquez, C.; Bixby, C.; Arrieta, A. The Microbiome and Metabolome of Preterm Infant Stool Are Personalized and Not Driven by Health Outcomes, Including Necrotizing Enterocolitis and Late-Onset Sepsis. mSphere 2018, 3. [CrossRef]

77. Chernikova, D.A.; Madan, J.C.; Housman, M.L.; Zain-Ul-Abideen, M.; Lundgren, S.N.; Morrison, H.G.; Sogin, M.L.; Williams, S.M.; Moore, J.H.; Karagas, M.R.; et al. The premature infant gut microbiome during the first 6 weeks of life differs based on gestational maturity at birth. Pediatr. Res. 2018, 84, 71-79. [CrossRef]

78. Brooks, B.; Firek, B.A.; Miller, C.S.; Sharon, I.; Thomas, B.C.; Baker, R.; Morowitz, M.J.; Banfield, J.F. Microbes in the neonatal intensive care unit resemble those found in the gut of premature infants. Microbiome 2014, 2, 1. [CrossRef] 
79. Ho, T.T.B.; Groer, M.W.; Kane, B.; Yee, A.L.; Torres, B.A.; Gilbert, J.A.; Maheshwari, A. Dichotomous development of the gut microbiome in preterm infants. Microbiome 2018, 6, 157. [CrossRef]

80. Drell, T.; Lutsar, I.; Stsepetova, J.; Parm, U.; Metsvaht, T.; Ilmoja, M.L.; Simm, J.; Sepp, E. The development of gut microbiota in critically ill extremely low birth weight infants assessed with 16S rRNA gene based sequencing. Gut Microbes 2014, 5, 304-312. [CrossRef]

81. Puri, K.; Taft, D.H.; Ambalavanan, N.; Schibler, K.R.; Morrow, A.L.; Kallapur, S.G. Association of Chorioamnionitis with Aberrant Neonatal Gut Colonization and Adverse Clinical Outcomes. PLoS ONE 2016, 11, e0162734. [CrossRef]

82. Chernikova, D.A.; Koestler, D.C.; Hoen, A.G.; Housman, M.L.; Hibberd, P.L.; Moore, J.H.; Morrison, H.G.; Sogin, M.L.; Zain-ul-abideen, M.; Madan, J.C. Fetal exposures and perinatal influences on the stool microbiota of premature infants. J. Matern.-Fetal Neonatal Med. 2016, 29, 99-105. [CrossRef]

83. Arboleya, S.; Sanchez, B.; Milani, C.; Duranti, S.; Solis, G.; Fernandez, N.; de los Reyes-Gavilan, C.G.; Ventura, M.; Margolles, A.; Gueimonde, M. Intestinal microbiota development in preterm neonates and effect of perinatal antibiotics. J. Pediatr. 2015, 166, 538-544. [CrossRef] [PubMed]

84. Stewart, C.J.; Embleton, N.D.; Clements, E.; Luna, P.N.; Smith, D.P.; Fofanova, T.Y.; Nelson, A.; Taylor, G.; Orr, C.H.; Petrosino, J.F.; et al. Cesarean or Vaginal Birth Does Not Impact the Longitudinal Development of the Gut Microbiome in a Cohort of Exclusively Preterm Infants. Front. Microbiol. 2017, 8, 1008. [CrossRef]

85. Dardas, M.; Gill, S.R.; Grier, A.; Pryhuber, G.S.; Gill, A.L.; Lee, Y.H.; Guillet, R. The impact of postnatal antibiotics on the preterm intestinal microbiome. Pediatr. Res. 2014, 76, 150-158. [CrossRef]

86. Brooks, B.; Olm, M.R.; Firek, B.A.; Baker, R.; Thomas, B.C.; Morowitz, M.J.; Banfield, J.F. Strain-resolved analysis of hospital rooms and infants reveals overlap between the human and room microbiome. Nat. Commun. 2017, 8, 1814. [CrossRef] [PubMed]

87. Taft, D.H.; Ambalavanan, N.; Schibler, K.R.; Yu, Z.; Newburg, D.S.; Deshmukh, H.; Ward, D.V.; Morrow, A.L. Center Variation in Intestinal Microbiota Prior to Late-Onset Sepsis in Preterm Infants. PLoS ONE 2015, 10, e0130604. [CrossRef] [PubMed]

88. Neu, J.; Walker, W.A. Necrotizing enterocolitis. N. Engl. J. Med. 2011, 364, 255-264. [CrossRef] [PubMed]

89. Fitzgibbons, S.C.; Ching, Y.; Yu, D.; Carpenter, J.; Kenny, M.; Weldon, C.; Lillehei, C.; Valim, C.; Horbar, J.D.; Jaksic, T. Mortality of necrotizing enterocolitis expressed by birth weight categories. J. Pediatr. Surg. 2009, 44, 1072-1075. [CrossRef]

90. De la Cochetiere, M.F.; Piloquet, H.; des Robert, C.; Darmaun, D.; Galmiche, J.P.; Roze, J.C. Early intestinal bacterial colonization and necrotizing enterocolitis in premature infants: The putative role of Clostridium. Pediatr. Res. 2004, 56, 366-370. [CrossRef]

91. Heida, F.H.; Harmsen, H.J.; Timmer, A.; Kooi, E.M.; Bos, A.F.; Hulscher, J.B. Identification of bacterial invasion in necrotizing enterocolitis specimens using fluorescent in situ hybridization. J. Perinatol. 2017, 37, 67-72. [CrossRef]

92. Warner, B.B.; Deych, E.; Zhou, Y.; Hall-Moore, C.; Weinstock, G.M.; Sodergren, E.; Shaikh, N.; Hoffmann, J.A.; Linneman, L.A.; Hamvas, A.; et al. Gut bacteria dysbiosis and necrotising enterocolitis in very low birthweight infants: A prospective case-control study. Lancet 2016, 387, 1928-1936. [CrossRef]

93. Mai, V.; Young, C.M.; Ukhanova, M.; Wang, X.; Sun, Y.; Casella, G.; Theriaque, D.; Li, N.; Sharma, R.; Hudak, M.; et al. Fecal microbiota in premature infants prior to necrotizing enterocolitis. PLoS ONE 2011, 6, e20647. [CrossRef]

94. Wang, Y.; Hoenig, J.D.; Malin, K.J.; Qamar, S.; Petrof, E.O.; Sun, J.; Antonopoulos, D.A.; Chang, E.B.; Claud, E.C. 16S rRNA gene-based analysis of fecal microbiota from preterm infants with and without necrotizing enterocolitis. ISME J. 2009, 3, 944-954. [CrossRef] [PubMed]

95. Torrazza, R.M.; Ukhanova, M.; Wang, X.; Sharma, R.; Hudak, M.L.; Neu, J.; Mai, V. Intestinal microbial ecology and environmental factors affecting necrotizing enterocolitis. PLoS ONE 2013, 8, e83304. [CrossRef] [PubMed]

96. Sim, K.; Shaw, A.G.; Randell, P.; Cox, M.J.; McClure, Z.E.; Li, M.S.; Haddad, M.; Langford, P.R.; Cookson, W.O.; Moffatt, M.F.; et al. Dysbiosis anticipating necrotizing enterocolitis in very premature infants. Clin. Infect. Dis. 2015, 60, 389-397. [CrossRef] [PubMed]

97. McMurtry, V.E.; Gupta, R.W.; Tran, L.; Blanchard, E.E.T.; Penn, D.; Taylor, C.M.; Ferris, M.J. Bacterial diversity and Clostridia abundance decrease with increasing severity of necrotizing enterocolitis. Microbiome 2015, 3, 11. [CrossRef] [PubMed] 
98. Stewart, C.J.; Marrs, E.C.; Magorrian, S.; Nelson, A.; Lanyon, C.; Perry, J.D.; Embleton, N.D.; Cummings, S.P.; Berrington, J.E. The preterm gut microbiota: Changes associated with necrotizing enterocolitis and infection. Acta Paediatr. 2012, 101, 1121-1127. [CrossRef]

99. Morrow, A.L.; Lagomarcino, A.J.; Schibler, K.R.; Taft, D.H.; Yu, Z.; Wang, B.; Altaye, M.; Wagner, M.; Gevers, D.; Ward, D.V.; et al. Early microbial and metabolomic signatures predict later onset of necrotizing enterocolitis in preterm infants. Microbiome 2013, 1, 13. [CrossRef] [PubMed]

100. Stewart, C.J.; Embleton, N.D.; Marrs, E.C.; Smith, D.P.; Nelson, A.; Abdulkadir, B.; Skeath, T.; Petrosino, J.F.; Perry, J.D.; Berrington, J.E.; et al. Temporal bacterial and metabolic development of the preterm gut reveals specific signatures in health and disease. Microbiome 2016, 4, 67. [CrossRef]

101. Normann, E.; Fahlen, A.; Engstrand, L.; Lilja, H.E. Intestinal microbial profiles in extremely preterm infants with and without necrotizing enterocolitis. Acta Paediatr. 2013, 102, 129-136. [CrossRef]

102. Rakoff-Nahoum, S.; Paglino, J.; Eslami-Varzaneh, F.; Edberg, S.; Medzhitov, R. Recognition of commensal microflora by toll-like receptors is required for intestinal homeostasis. Cell 2004, 118, 229-241. [CrossRef]

103. Patel, R.M.; Denning, P.W. Intestinal microbiota and its relationship with necrotizing enterocolitis. Pediatr. Res. 2015, 78, 232-238. [CrossRef] [PubMed]

104. Stewart, C.J.; Embleton, N.D.; Marrs, E.C.; Smith, D.P.; Fofanova, T.; Nelson, A.; Skeath, T.; Perry, J.D.; Petrosino, J.F.; Berrington, J.E. Longitudinal development of the gut microbiome and metabolome in preterm neonates with late onset sepsis and healthy controls. Microbiome 2017, 5, 75. [CrossRef] [PubMed]

105. Sanidad, K.Z.; Zeng, M.Y. LOS in the Dysbiotic Gut. Cell. Host. Microbe. 2020, 27, 11-13. [CrossRef] [PubMed]

106. Lee, L.-H.; Letchumanan, V.; Khan, T.M.; Chan, K.-G.; Goh, B.-H.; Ab Mutalib, N.-S. IDDF2019-ABS-0322 Dissecting the Gut and Skin: Budding Association between Gut Microbiome in the Development to Psoriasis? BMJ Publishing Group: London, UK, 2019.

107. Lee, L.-H.; Letchumanan, V.; Khan, T.M.; Long, M.; Chan, K.-G.; Goh, B.-H.; Ab Mutalib, N.-S. IDDF2018-ABS-0240 Role of Human Microbiota in Skin Dermatitis and Eczema: A Systematic Review; BMJ Publishing Group: London, UK, 2018.

108. Lee, L.-H.; Ser, H.-L.; Khan, T.M.; Gan, K.-G.; Goh, B.-H.; Mutalib, N.-S.A. Association between gut microbiota and autism spectrum disorder: A systematic review and meta-analysis. Gut 2019, 68, A40-A41. [CrossRef]

109. Lee, L.-H.; Ser, H.-L.; Khan, T.M.; Long, M.; Chan, K.-G.; Goh, B.-H.; Ab Mutalib, N.-S. IDDF2018-ABS-0239 Dissecting the Gut and Brain: Potential Links between Gut Microbiota in Development of Alzheimer's Disease? BMJ Publishing Group: London, UK, 2018.

110. Durganaudu, H.; Kunasegaran, T.; Ramadas, A. Dietary glycaemic index and type 2 diabetes mellitus: Potential modulation of gut microbiota. Prog. Microbes Mol. Biol. 2020, 3, a0000082. [CrossRef]

111. Selvaraj, S.M.; Wong, S.H.; Ser, H.-L.; Lee, L.-H. Role of low FODMAP diet and probiotics on gut microbiome in irritable bowel disease (IBS). Prog. Microbes Mol. Biol. 2020, 3, A0000069. [CrossRef] 